\title{
UN PERRO EN CUADRANTES DE UNTIKESKEN
}

La ceca de Untikesken utilizó diseños bastante estables para identificar visualmente el valor de las denominaciones que acuñó. Éstos fueron el Pegaso para los ases/ unidades, el toro para los semis, el león para los cuadrantes y el caballo o la cabeza de caballo para los sextantes. Sólo las monedas CNH 180/21-26, se apartaron de forma puntual de esta pauta general, utilizando el león para las unidades, el caballo marino para las mitades, el gallo para los cuartos y el jabalí para los sextos.

En estas líneas queremos presentar una nueva pieza de Untikesken que después de su análisis pensamos que muestra un tipo de reverso nuevo. Se trata de un perro sobre una pieza de $3,51 \mathrm{~g}$, que por su peso podría conceptuarse como un cuadrante.

La identificación de este nuevo diseño no está exenta de algunas incertidumbres, debidas a la conservación de la pieza, al reducido espacio en el que se grabó el diseño y a que, tratándose de un carnívoro, tiene muchas similitudes con otros animales de la misma especie o emparentados.
La pieza en cuestión se describe del siguiente modo:

AE. 15 mm. 3,51 g (fig. 1).

Anv. Cabeza galeada de Minerva, a dcha.

Rev. Perro saltando, a dcha.; la cola está levantada y enroscada; sobre línea, la leyenda ibérica $\uparrow[N \psi<3]<\uparrow$ u[ntikes]ken.

Pertenece a la col. G. Cores (Madrid).

Lo primero que viene a la mente de quienes ven la pieza es que se trata de un león, ya que como se ha dicho ese es el diseño mayoritario empleado por la ceca para los cuadrantes. Muestra una disposición bastante similar, dado que está representado de cuerpo entero y de perfil, a derecha. Cuando se mira la otra cara no pasa desapercibido el estilo del retrato de Minerva, que se diferencia del que tienen la mayoría de piezas del taller, no sólo de los cuadrantes, sino también de las denominaciones mayores. Sólo un tipo de ases tiene una fisonomía de retrato de Minerva que se aproxima al que tiene la moneda que 


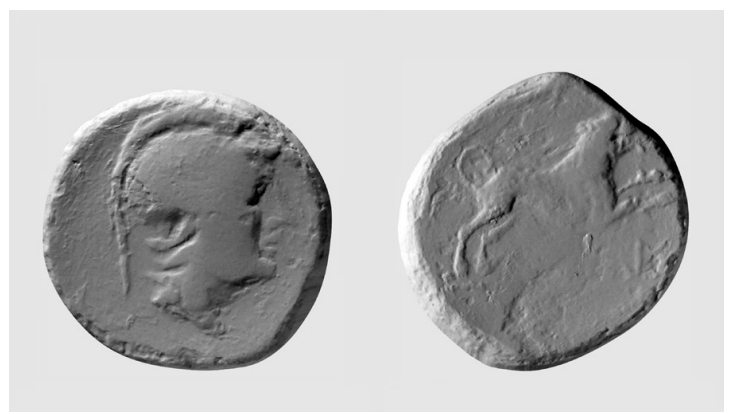

Fig. 1. Madrid. Col. Cores. (x2).

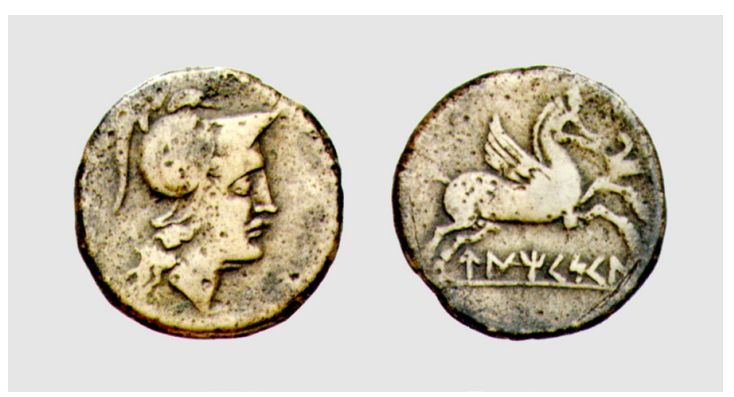

Fig. 2. Subasta Áureo 25/10/2006, lote 65 .

estamos comentando (fig. 2). Se trata del tipo $\mathrm{CNH}$ $150 / 61$, del que se conocen siete monedas; con un peso medio de 16,62 g, estas piezas se sitúan en una posición relativamente avanzada dentro de la horquilla de pesos de las emisiones de ases / unidades de Untikesken, que oscila entre 24,68 g para las más antiguas y 11,29 g para las más modernas.

En la época en la que se acuñó nuestro cuadrante, $\mathrm{ca}$. finales del s. II, estas monedas fueron escasas $(\mathrm{CNH}$ $146 / 34,3,50 \mathrm{~g}, 147 / 45$, sin peso conocido, 148/47, 3,88 g). Los pesos de estas piezas y los que tienen los semis con reverso toro embistiendo permiten proponer que la moneda, de acuerdo con su peso, encaja perfectamente dentro de la denominación cuarto, con un estándar de peso un poco reducido en relación con los de las emisiones de la primera mitad del s. II a.C.

Por consiguiente, todo parece indicar que podría tratase de una moneda de las últimas décadas del s. II o comienzos del I a.C. En relación con los cuadrantes que se conocen no muestra similitudes con ninguno, por lo que debe tratarse de una acuñación diferenciada de las que ya han sido documentadas; en este caso es posible que se acuñara junto con otras denominaciones.

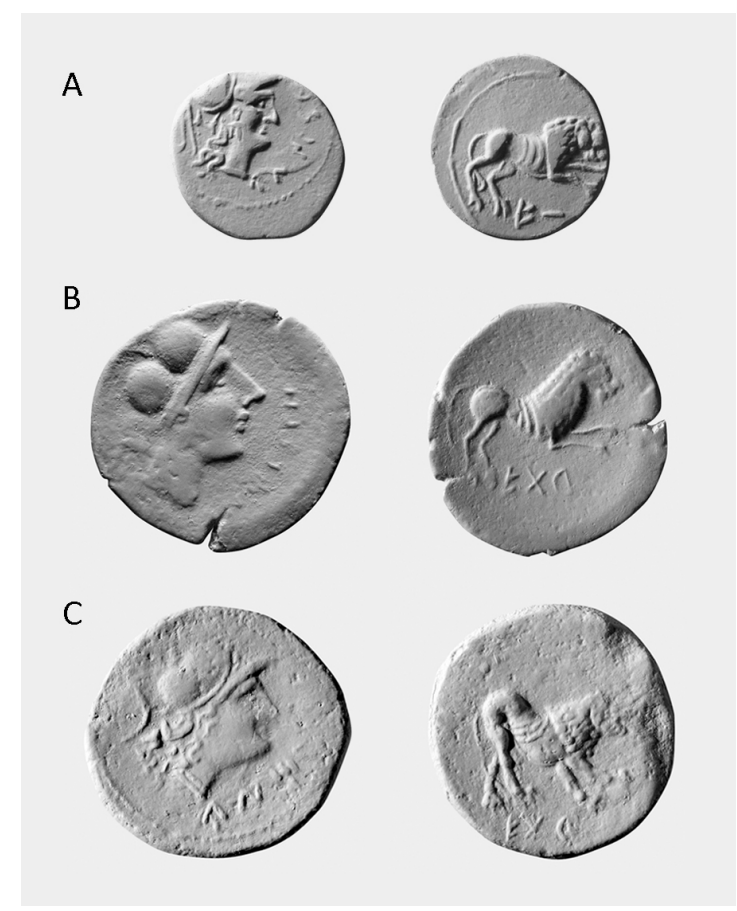

Fig. 3. A: Londres, The British Museum. B: Copenhague, The Danish National Museum. C: Madrid, col. Cores.

Ya hemos comentado que el anverso guarda una cierta similitud con las monedas $C N H$ 61, que serían con las únicas que podrían relacionarse.

A pesar de que todo parece indicar que estamos ante una acuñación que debe diferenciarse de las que ya se conocen, lo que consideramos más singular de la moneda es el reverso. El diseño que muestra, como ya hemos avanzado, sería un perro. Existen algunos detalles que permiten diferenciar el diseño de nuestra moneda del león, que es con el que podría confundirse.

Untikesken fue bastante sistemática con la postura con la que muestra el león y con la disposición de las diversas partes anatómicas, de las que interesa destacar la cabeza y la cola. Por lo que respecta a la cabeza, que siempre lleva melena, ésta siempre aparece orientada hacia abajo (fig. 3); mientras que la cola siempre desciende hasta situarse entre las patas y enroscarse al final (en los tipos CNH 144/21-23 desciende bastante recta, sin enroscamiento final). Las costillas están siempre marcadas (fig. 3).

En cambio, la figura que se representa en nuestra moneda muestra una disposición diferente (fig. 1), no sólo en la postura, que ya denota un tipo específico de animal, sino también en la postura de la cabeza y de la 


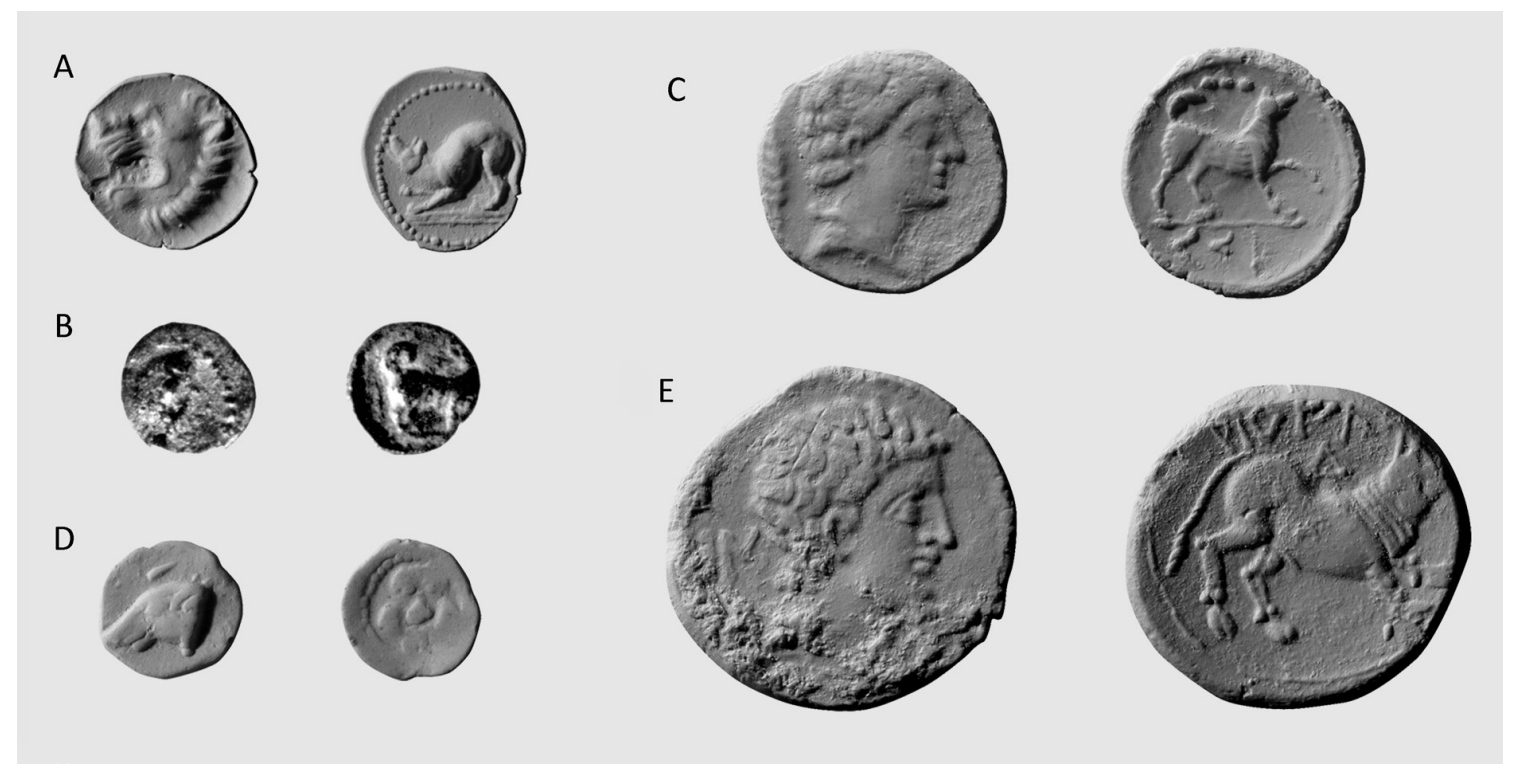

Fig. 4. A: Barcelona, col. privada. B: Barcelona, ex col. Baucis. C: Madrid, col. Cores. D: Barcelona, GNC 20505, del tesoro de Pont de Molins. E: Madrid, col. Cores. Todas las imágenes x2.

cola. Efectivamente, la cabeza está levantada y mira hacia arriba; además, la boca está un poco abierta y parece que tenga la lengua un poco salida por un lateral; no lleva melena, la cual siempre ha sido grabada en los leones con una cierta ostentosidad.

En la moneda de Untikesken que ahora presentamos, la postura es difícil calificarla de ataque o de alegría, debido a su pequeño tamaño y regular acuñación. No obstante, todo parece indicar que lo que se grabó no fue un león, ya que se aparta totalmente de las distintas convenciones utilizadas en Untikesken para representar a un león.

El perro no fue un animal utilizado con frecuencia en las acuñaciones de la península Ibérica (sobre el perro en el mundo ibérico, vease Mata et al. 2014:51-53); en una actitud de alerta previo al ataque lo vemos en fraccionarias ampuritanas (Villaronga 1997: $\mathrm{n}^{\circ}$ 221-244) (fig. 4, A); caminando al paso en fraccionarias ampuritanas (Villaronga 1997: $\mathrm{n}^{\circ}$ 441-442) (fig. 4, B) y Kese ( $\mathrm{CNH}$ 164/46) (fig. 4, C); es posible que haya que identificar como una cabeza de perro lo que se muestra en unas raras fraccionarias ampuritanas (Villaronga 1997: $n^{\circ}$ 427) (fig. 4, D); también el animal que aparece en algunos reversos de Abariltur (CNH 203-204/3 y 6) (fig. 4, E) creemos que podría identificarse como un perro, aunque haya sido tradicionalmente descrito como un toro. De todos ellos, los que se representan marchando al paso (Kese y Emporion) son los que se muestran en una actitud más parecida a la de nuestra pieza.

Por tanto, creemos que existen argumentos convincentes para creer que la pieza que ahora publicamos está representando a un perro.

$$
\begin{array}{r}
\text { GonZalo Cores Uría } \\
\text { coresgonzalo8@gmail.com } \\
\text { Pere Pau Ripollès Alegre } \\
\text { Dept. Prehistòria i Arqueologia } \\
\text { Universitat de València } \\
\text { Pere.P.Ripolles@uv.es }
\end{array}
$$

\section{BIBLIOGRAFÍA}

CNH: VILLARONGA, L. (1994): Corpus nummum hispaniae ante augusti aetatem, Madrid.

MATA, C.; BONET, H.; COLLADO, E.; FUENTES, M.; IZQUIERDO, I.; MARLASCA, R.; MORENO, A.; PASCUAL, J. LL.; QUESADA, F.; QUIXAL, D.; RIPOLLÈS, P. P.; SANCHIS, A.; SORIA, L.; TORMO, C. (2014): Fauna ibérica. De lo real a lo imaginario (II), Trabajos Varios del SIP, 117, Valencia.

VILLARONGA, L. (1997): Monedes de plata emporitanes dels segles V-IV a.C., Barcelona 